\title{
Semi-Autonomous Robotic Sampler for Explosives Residues in Surface Soils
}

James H. Lever, Thomas Nichols, Daniel Denton, Ryan Meador, Allison Morlock, Jason Kenyon, Kaitlin Palmer, and Philip G. Thorne ${ }^{\dagger}$

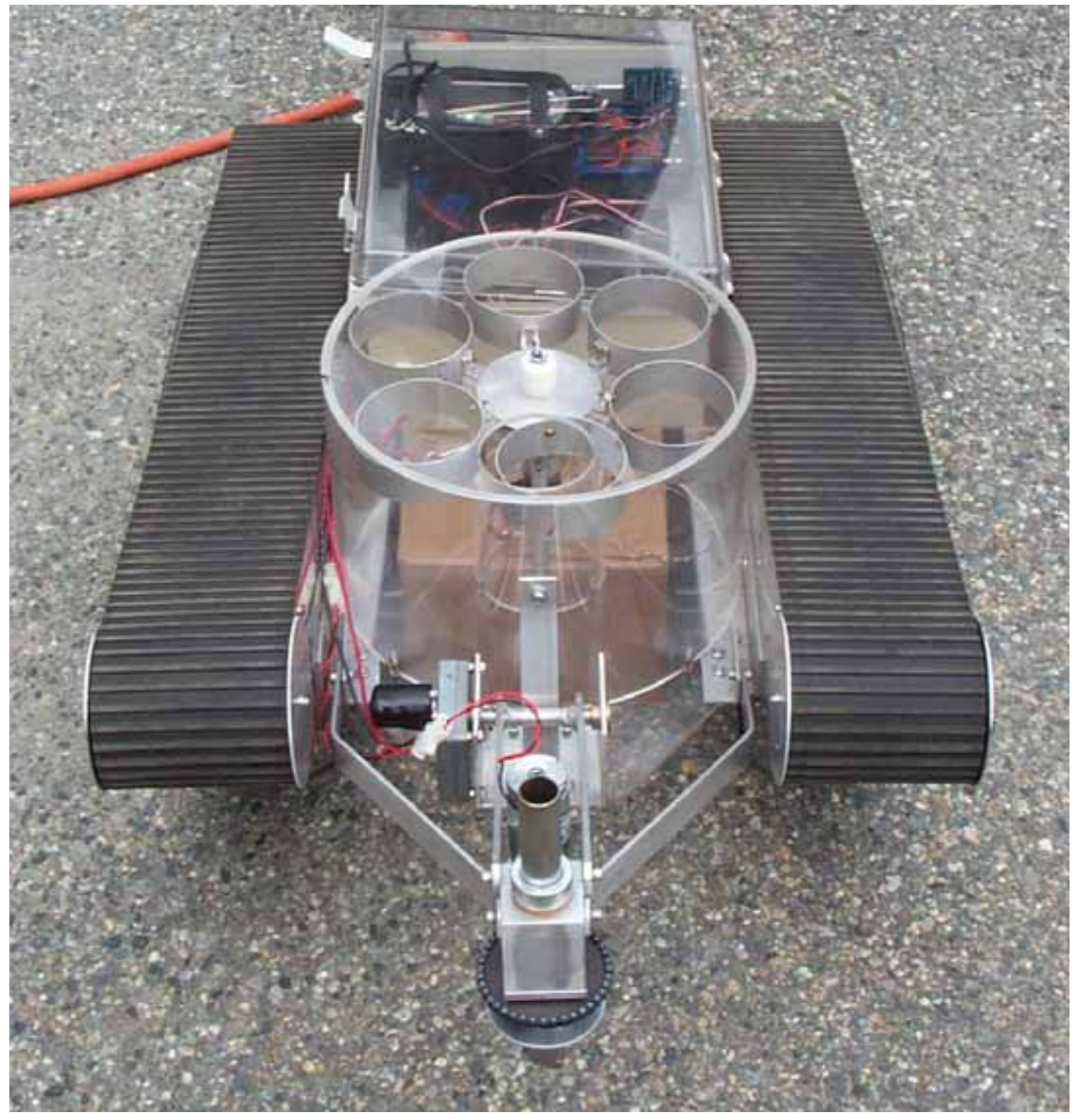





\section{Semi-Autonomous Robotic Sampler for Explosives Residues in Surface Soils}

James H. Lever,* Thomas Nichols,* Daniel Denton,* Ryan Meador,* Allison Morlock, ${ }^{*}$ Jason Kenyon, ${ }^{\star}$ Kaitlin Palmer, ${ }^{\star}$ Philip G. Thorne ${ }^{\dagger}$

*Cold Regions Research and Engineering Laboratory U.S. Army Engineer Research and Development Center

72 Lyme Road

Hanover, New Hampshire 03755

$\dagger$ Applied Research Associates

415 Waterman Road

South Royalton, VT 05068

Approved for public release; distribution is unlimited 


\section{ABSTRACT}

A 25-kg, dual-track robot was built to satisfy the sampling protocol for surface explosives residues in soils. A rotary-tube cutter takes fairly consistent samples in a variety of soil conditions. Each sample bag holds about 30 samples to form a composite that represents the sampled area. An onboard carousel holds six bags: five composite samples and a sixth bag to clean the tube to minimize cross-contamination. We designed the robot to operate autonomously to collect a composite sample, log the coordinates of the area sampled, complete a composite within about 20 minutes, and operate without intervention for about 2 hours. A person may tele-operate the robot between sampling areas and to and from a base station where batteries and sample bags may be replenished.

DISCLAIMER: The contents of this report are not to be used for advertising, publication, or promotional purposes. Citation of trade names does not constitute an official endorsement or approval of the use of such commercial products. All product names and trademarks cited are the property of their respective owners. The findings of this report are not to be construed as an official Department of the Army position unless so designated by other authorized documents. 


\section{CONTENTS}

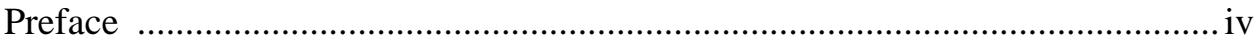

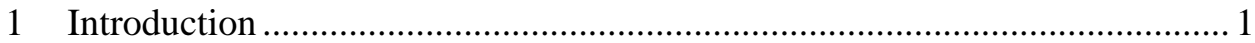

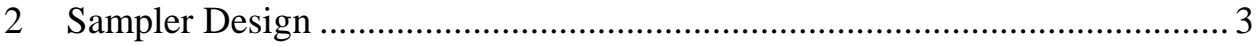

3 Laboratory and Field Tests...................................................................... 13

4 Conclusions and Future Work ................................................................ 17

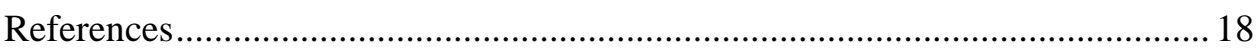

\section{ILLUSTRATIONS}

Figure 1. Sampling devices tested for soil-type versatility and sample-volume consistency.

Figure 2. Sample volume consistency for open-teeth and closed-teeth cutters of

2.5-cm and 5-cm diameters and three soil types.

Figure 3. Efficiency of the selected cutter for collection of 1-mm-diameter steel balls scattered on the soil surface............................................................ 7

Figure 4. Sampling system mounted to SnoBot................................................... 9

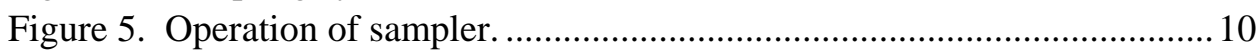

Figure 6. Sampler control system hardware...................................................... 11

Figure 7. Histogram of 31 samples acquired autonomously in sequence...........13

Figure 8. Cumulative and discrete-sample masses of 31 samples acquired autonomously in sequence.

Figure 9. Sampler executing autonomous sampling sequence along an access road adjacent to targets on an anti-tank range at CFB Gagetown.

Figure 10. Sampler executing autonomous sampling sequence on impact area of a hand-grenade range at CFB Gagetown. 15

\section{TABLES}

Table 1. Comparison of HE concentrations in soils collected by human and robotic samplers at CFB Gagetown, October 2003. 


\section{PREFACE}

This report was prepared by Dr. James H. Lever, Mechanical Engineer, Thomas Nichols, graduate student intern, Daniel Denton, Ryan Meador, Allison Morlock, Jason Kenyon, Kaitlin Palmer, all student interns, U.S. Army Engineer Research and Development Center (ERDC), Cold Regions Research and Engineering Laboratory (CRREL), Hanover, New Hampshire, and Philip G. Thorne senior scientist, Applied Research Associates.

This work was funded by the U.S. Army Environmental Center under the direction of Martin Stutz. Their corresponding report number is SFIM-AEC-ATCR-2004006.

The authors thank the many CRREL scientists who helped establish performance criteria of the sampler, including Dr. Thomas Jenkins, Marianne Walsh, Susan Taylor, Alan Hewitt, Michael Walsh and Dr. Gary Phetteplace. We also thank Dr. Laura Ray, Dartmouth College, for her advice on navigation strategies. Fabrication support was provided by Bill Burch, Chris Donnely, Jim Morse, and Jesse Stanley.

The Commander and Executive Director of the Engineer Research and Development Center is COL James R. Rowan, EN. The Director is Dr. James R. Houston. 


\title{
Semi-Autonomous Robotic Sampler for Explosives Residues in Surface Soils
}

\author{
JAMES H. LEVER, THOMAS NICHOLS, DANIEL DENTON, RYAN MEADOR, \\ ALLISON MORLOCK, JASON KENYON, KAITLIN PALMER, AND \\ PHILIP G. THORNE
}

\section{INTRODUCTION}

Use of high-explosive (HE) ordinance on live-fire training ranges has resulted in contamination of surface soils by explosives residues (Jenkins et al. 2001). The contamination consists of HE particles scattered over the surface (Hewitt et al. 2003). The particles span a broad size range, from sub-millimeter to several centimeters, depending on the munition and the order of the detonation (Taylor et al. 2004). Dissolution of these particles can result in contamination of ground water and migration of explosives residues off base.

Quantifying the concentration of explosives residues in surface soils is essential for cost-effective remedial operations at FUDS and BRAC sites and to sustain use of live-fire training ranges. Because the particles are heterogeneously distributed across the soil surface, measuring their concentration demands adherence to a rigorous sampling protocol that is tedious to execute and can expose human samplers to risks from unexploded ordnance (UXO). The presence of submunitions on a range excludes manual sampling entirely.

Human samplers undertake two sampling strategies: stratified random and judgmental sampling. Stratified-random sampling consists of sampling soils on a pre-determined rectangular grid, without regard for the presence of objects of interest within the grid. A large number of surface-soil samples are taken (roughly one sample per 1-2 $\mathrm{m}^{2}$ ) and combined into a composite sample for laboratory homogenization and analysis. This strategy quantifies the background concentration of HE within an area defined by the extent of the grid. Judgmental sampling consists of sampling near an object of interest, such as a UXO or firing target. A circular sampling pattern may be used, but generally samples are taken right up to the object of interest. This strategy quantifies the HE concentration in soils around "hot spots" on ranges. 
Our objective here was to demonstrate that an inexpensive robotic sampler could satisfy the sampling protocol for surface explosives residues and to explore the relationship between sampling protocol and robot mobility requirements. We used an existing 25-kg dual-track robot, and focused on two technical areas: developing a sampling device that can satisfy sampling requirements for a broad range of soil conditions and demonstrating sufficient autonomous navigation to execute stratified random sampling over a variety of terrain conditions. 


\section{SAMPLER DESIGN}

We began by conducting brainstorming sessions with scientists concerned with establishing sampling protocols for range characterization, including Thomas Jenkins, Marianne Walsh, Susan Taylor, Alan Hewitt and Michael Walsh. Consensus led to the following design criteria:

- Acquire many (30-50) small samples per 1-2 kg composite sample.

- Vertical coring (2-3 cm diameter, 2-5 cm) is preferable to area-based collection such as sweeping or skimming (to maintain connection to human-sampling techniques).

- Individual samples should be fairly uniform in volume.

- Surface particle collection efficiency should exceed 90\%.

- Be able to collect and store several composite samples without human intervention, with roughly 2 hours of operation.

- Minimize cross-contamination between samples.

- Be able to adapt to a wide variety of soil and terrain conditions.

- Execute stratified-random composite samples autonomously within a pre-defined area, but allow tele-operation between composites or for judgmental sampling.

- Robot should be easily transported by two persons (less than $40 \mathrm{~kg}$ ).

- Robot should be inexpensive to allow for possible loss by UXO detonation.

We examined numerous conventional soil-sampling devices (e.g., augers, corers) and determined that rotary cutting action was helpful for a lightweight robot to sample a variety of soil conditions. We then tested a variety of rotary cutting heads qualitatively for soil-type versatility and sample-volume consistency (Fig. 1). 


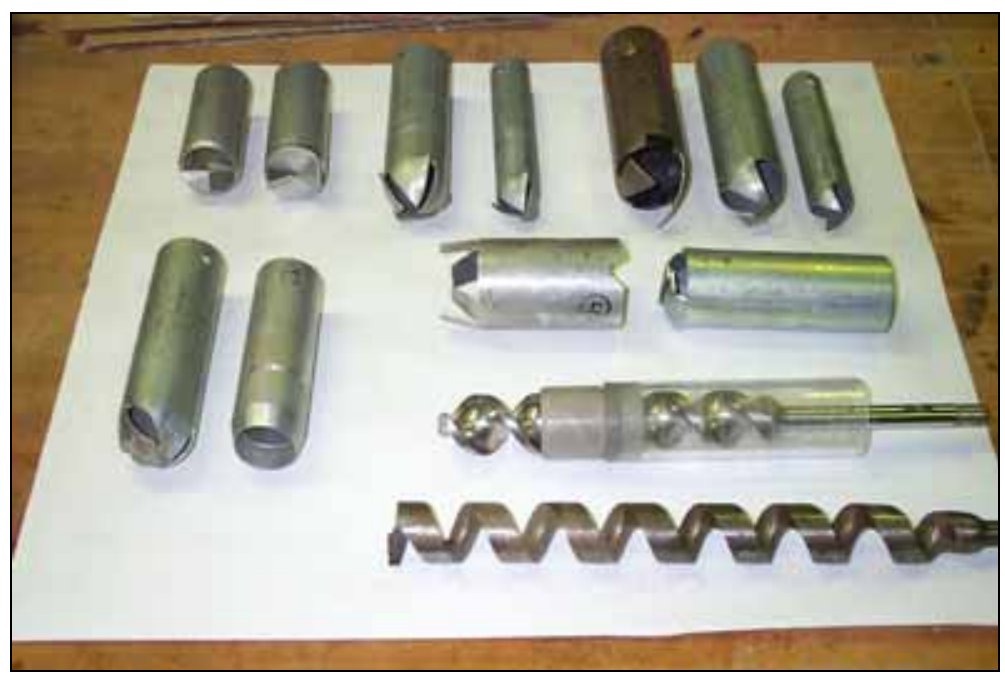

Figure 1. Sampling devices tested for soil-type versatility and sample-volume consistency. Cutters with closed teeth include the central one on the top row and the one to its left. The three cutters to its right have open teeth.

For soils with some moisture content, most of the cutting heads work well in terms of effort to penetrate the soil and soil retention when withdrawn. For dry sandy-gravely soils, cutters with the teeth closed off on the bottom retained the soil better than cutters with open teeth. Soil entered the closed cutters tangentially, and the teeth provide vertical support for the soil until it was tipped out the other end. Figure 2 compares the best four cutters tested for consistency of sample volume retained. Based on these tests, we selected the small $(2.5-\mathrm{cm})$ diameter, three-tooth closed cutter as the most promising sampling device. 


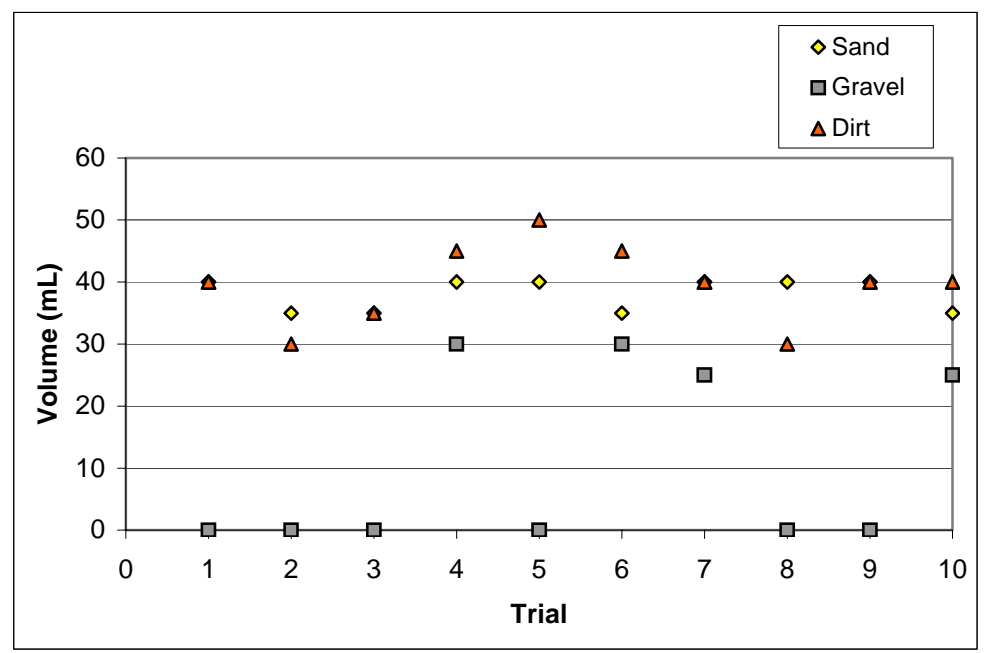

a. Open/small volume collected.

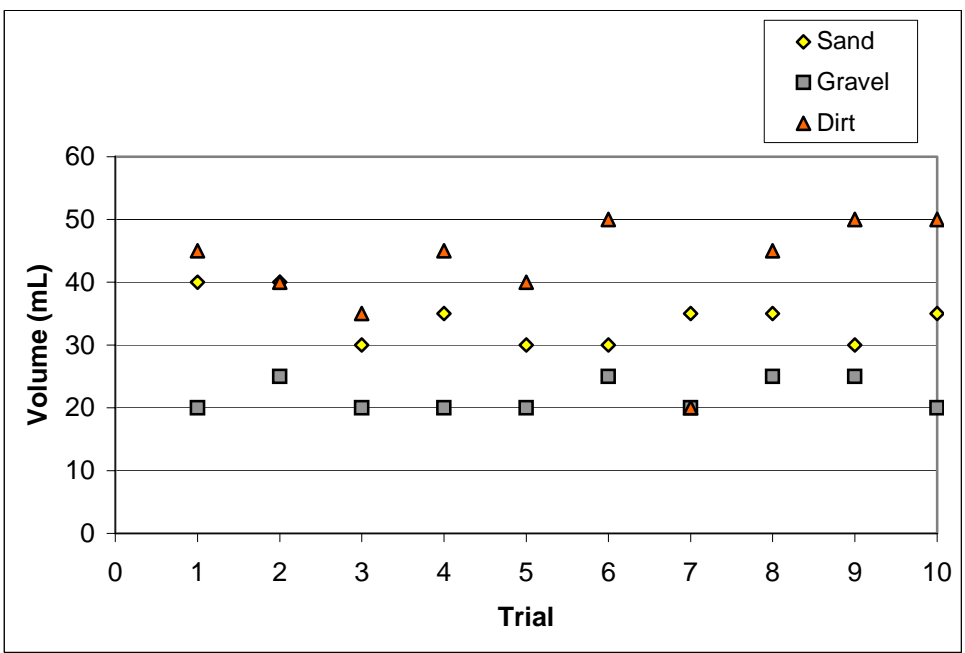

b. Closed/small volume collected.

Figure 2. Sample volume consistency for open-teeth and closed-teeth cutters of $2.5-\mathrm{cm}$ and $5-\mathrm{cm}$ diameters (small, large) and three soil types (sand, gravel, dirt or silty loam soil). Each symbol represents the volume of sample acquired for that trial. The closed, small-volume cutter produced the most consistent results. Because the cutter penetration was the same for each trial, variations in average sample volume reflect lofting of the various soil types. 


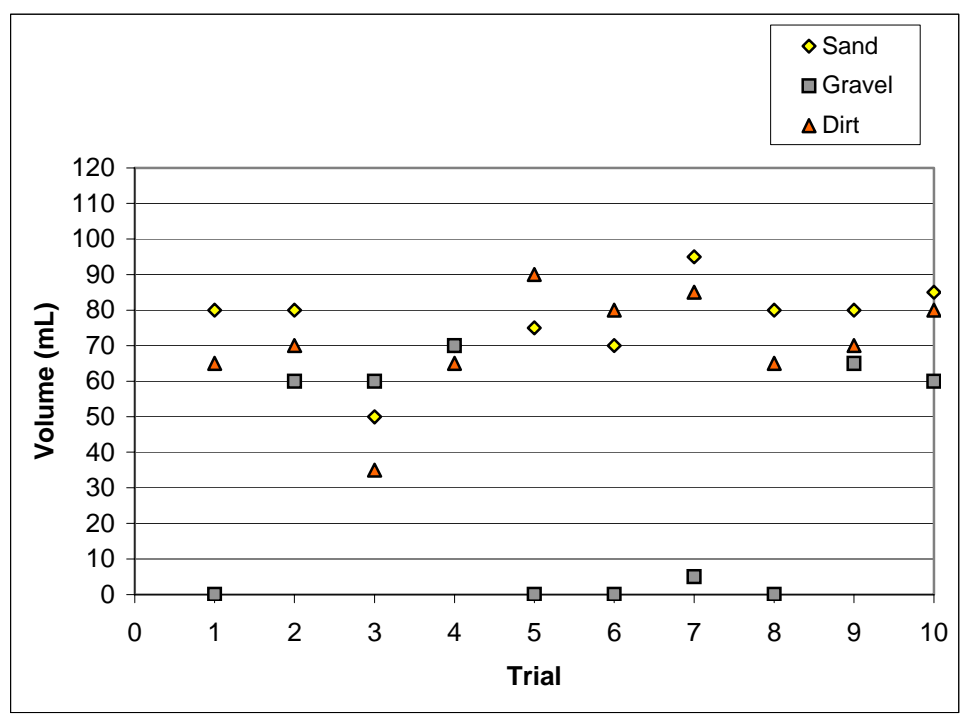

c. Open/large volume collected.

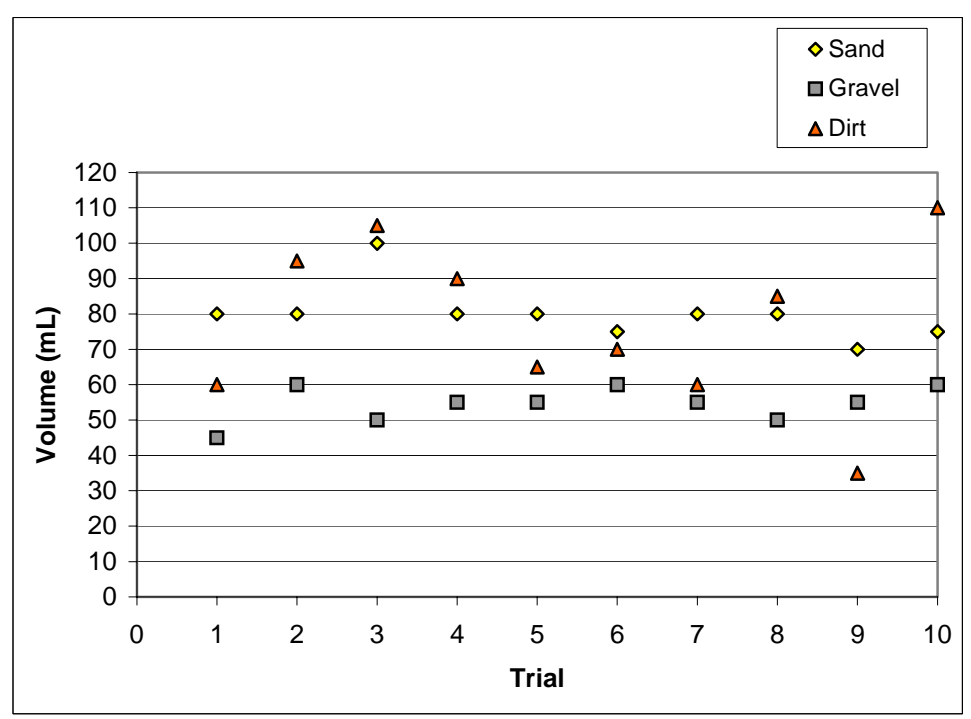

d. Closed/large volume collected.

Figure 2 (cont'd). Sample volume consistency for open-teeth and closedteeth cutters of $2.5-\mathrm{cm}$ and $5-\mathrm{cm}$ diameters (small, large) and three soil types (sand, gravel, dirt or silty loam soil). Each symbol represents the volume of sample acquired for that trial. The closed, small-volume cutter produced the most consistent results. Because the cutter penetration was the same for each trial, variations in average sample volume reflect lofting of the various soil types. 
We also conducted collection efficiency tests to ensure that the selected cutter would efficiently collect particles on the soil surface. We seeded 1-mmdiameter steel balls across the surface of gravely soil in a test bin. After sampling soil from the bin, we magnetically separated and measured the mass of balls collected (Fig. 3). Based on the average mass collected and the average areal density of the balls, the effective diameter for $100 \%$ collection efficiency was $3.54 \mathrm{~cm}$. This is essentially identical to the 3.5-cm-diameter hole that the cutter makes in the soil. The variations of the collected mass about the average are consistent with the visually observed variation in areal density of the balls scattered on the surface. We concluded that the selected cutter met our requirements for greater than $90 \%$ collection efficiency for surface particles on this soil type.

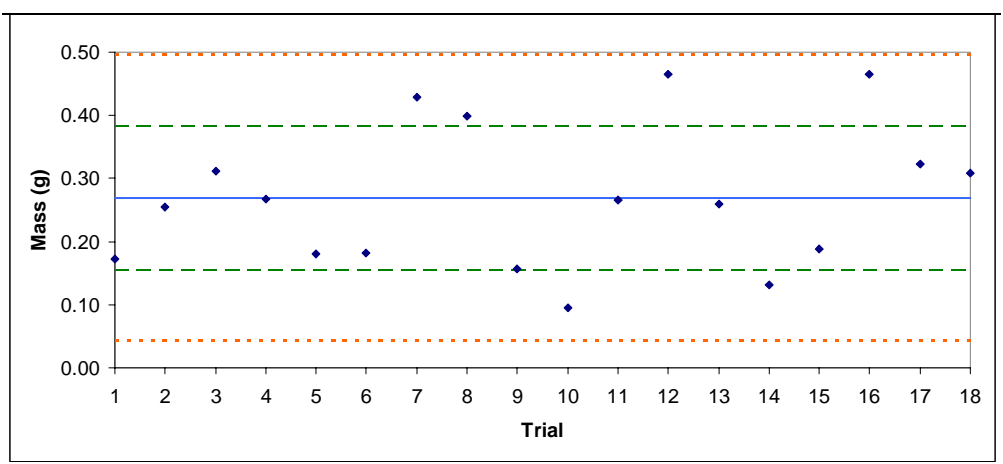

Figure 3. Efficiency of the selected cutter (3-tooth, 2.5-cm, closed design) for collection of 1-mm-diameter steel balls scattered on the soil surface. Each trial is one sample. The central line is the mass of balls expected based on uniform areal density and $3.5-\mathrm{cm}$ effective cutter diameter. The dashed lines are \pm 1 and \pm 2 standard deviations from the mean. The average collection efficiency is $100 \%$ and the scatter of the mass collected is within the variation of the distribution of balls seeded manually onto the soil surface. 
We designed the sampling system with the following features (Fig. 4):

- A rotary drive to rotate the cutting tube.

- A mount for the cutting tube that permits easy cutter changes for different soil types.

- A four-bar linkage to press the cutting tube into the soil with a near-vertical trajectory and tip it backwards to dump the sample into a collection bag.

- A carousel that carries six sample bags (five composite samples and one bag for cleaning cuts to minimize cross-contamination between composites).

- A load cell to support the active carousel arm to measure the mass of each discrete sample while collecting a composite sample.

- A structural mount to attach the sampling system to our robot as a single unit.

Figure 4 shows the sampling system mounted on CRREL's over-snow robot (SnoBot). The robot with sampler measures about 1-m-long $\times 0.55$-m-wide and weighs $30 \mathrm{~kg}$ with no samples on board. Figure 5 shows the intended operation of the sampling system.

We modified the robot's control system to achieve the following features:

- Increased memory and processing capacity to control the sampling system.

- Data acquisition for GPS coordinates, sample mass and position control on the four-bar linkage (i.e., sample arm) and carousel.

- Increased radio range (exceeding $150 \mathrm{~m}$ ). 


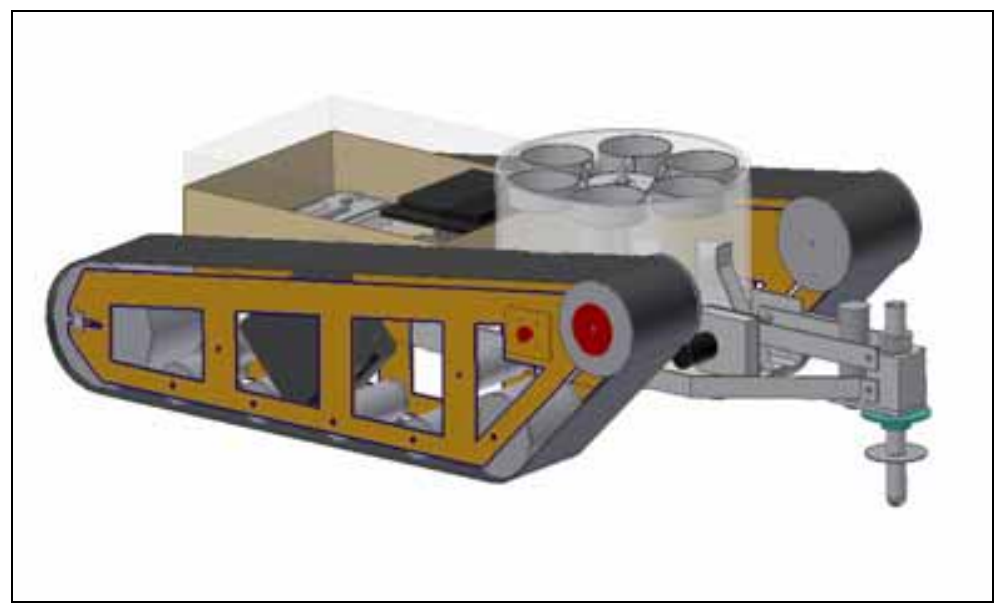

a. CAD representation.

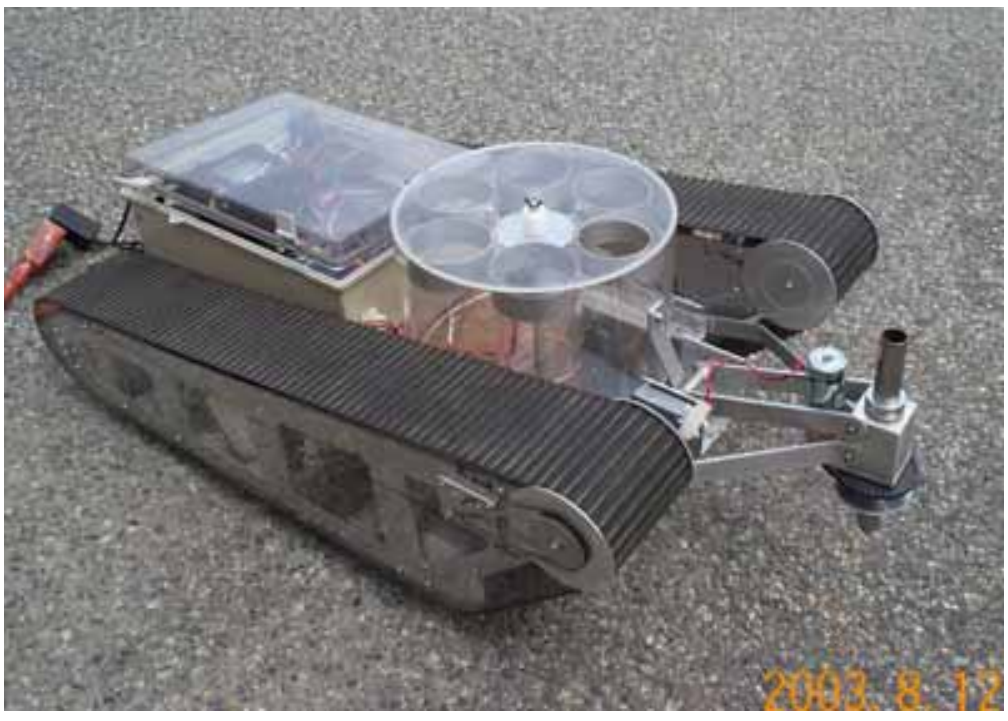

b. Photo.

Figure 4. Sampling system mounted to SnoBot (CRREL's over-snow robot). The cutter drive motor moves with the cutter on a four-bar linkage. The position-selectable six-bag carousel holds the composite samples formed from 30-50 discrete samples. The robot with sampler is about 1-m long and weighs about $30 \mathrm{~kg}$ empty. 


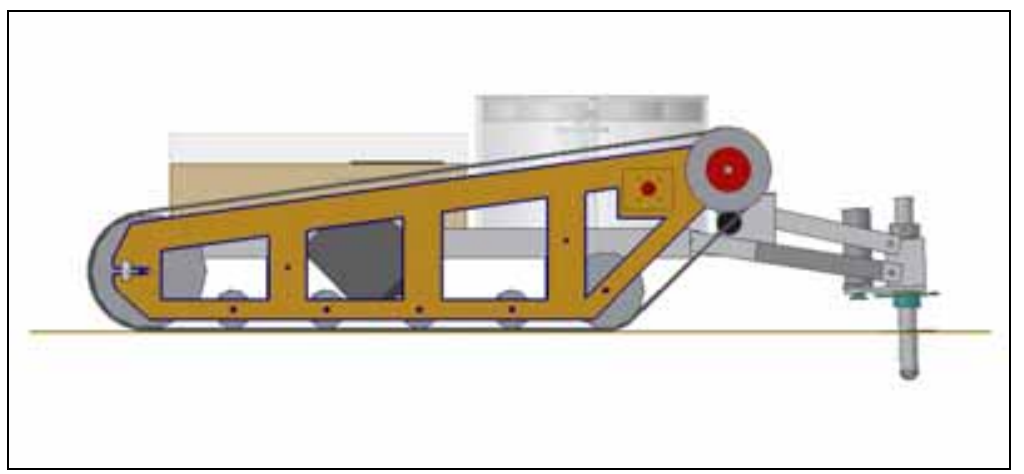

a. A four-bar linkage presses the rotating cutting tube into soil about 5-7 cm deep.

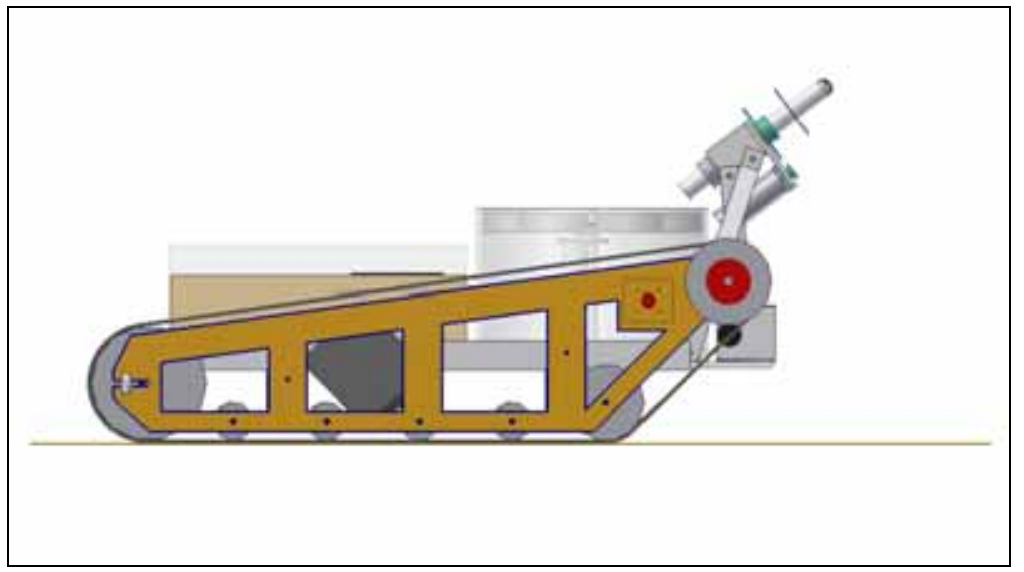

b. It then rotates upward to dump the collected sample into a bag held in six-bag carousel.

Figure 5. Operation of sampler. Each carousel bag can hold 30-50 discrete samples. A load cell measures the mass of each discrete sample to assess successful collection and consistency of the sample masses.

Figure 6 shows a schematic and a photo of the control system hardware. Operator input is via an interface program operating on a laptop computer or from a joystick connected to the laptop. The laptop communicates through a wireless Local Area Network (LAN) connection to an iPaq Personal Data Assistant (PDA) on the robot. The iPaq passes instructions along to a BasicStamp ${ }^{\circledR}$ microprocessor that controls the motors (via pulse-width-modulated, PWM, speed controllers), an 8-bit analog-digital converter (for position control and load cell measurements), and a serial multiplexer (to obtain data from the GPS or send data to a video on-screen display, OSD). 


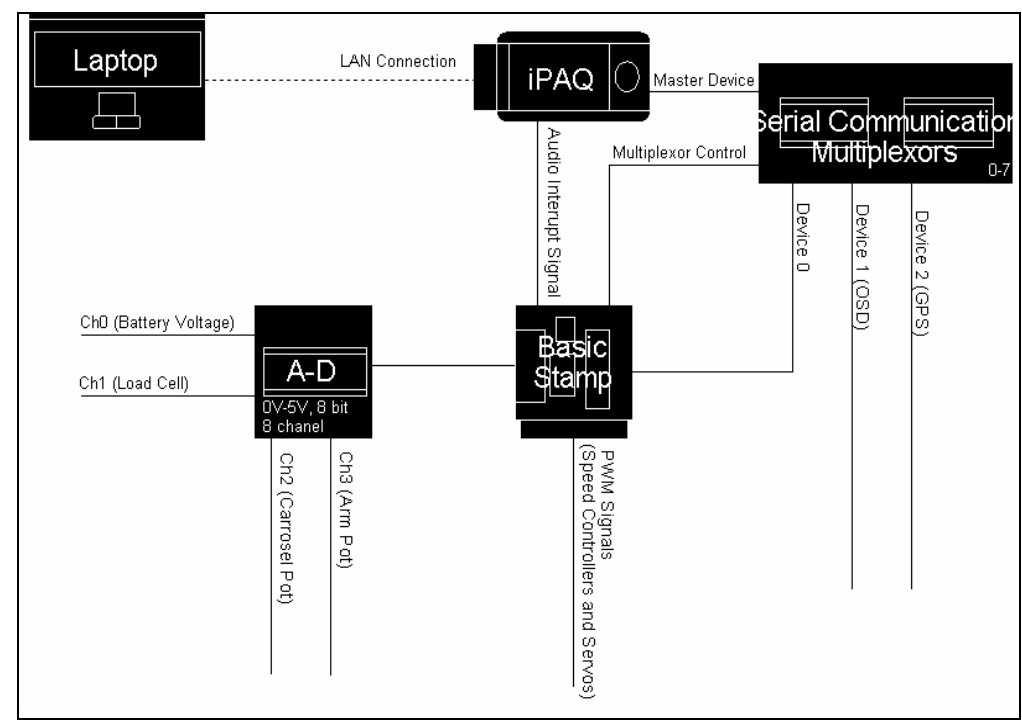

a. Schematic.

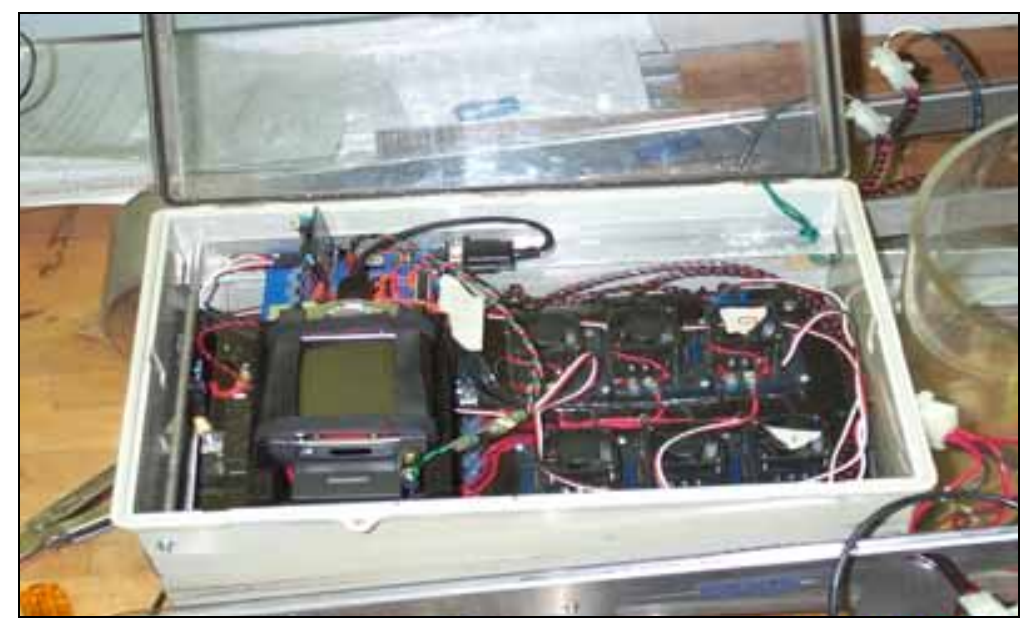

\section{b. Photo.}

Figure 6. Sampler control system hardware.

The robotic sampler can operate under manual control or autonomous-sampling mode. The latter permits automatic sample acquisition (sample cutting, dumping, mass measurement) with navigation controlled by the operator (i.e., tele-operation) for judgmental sampling. For stratified-random sampling, we implemented sequential autonomous sampling, where open-loop movement to the next sample position follows each discrete sample. Using this mode, a sequence 
of samples along nominally straight paths can be executed, with turns after each straight section to form a grid. The GPS coordinates of each sample can be logged, but at present we have not implemented closed-loop navigation to GPS waypoints. For stratified-random sampling, tight position control of each sample location is not critical provided the samples are spatially independent and distributed throughout the target area adequately to characterize the average HE concentration. We felt that more sophisticated navigation could be undertaken later once the sampler itself was validated. 


\section{LABORATORY AND FIELD TESTS}

We conducted laboratory tests in a soil bin (6.1-m $\times 3.7-\mathrm{m} \times 0.3$-m-deep) to assess the consistency of the discrete sample masses acquired during sequential semi-autonomous sampling. The soil was moist sand-gravel, and 5-6 discrete samples were possible along each straight section. Figures 7 and 8 show the resulting data. The discrete samples averaged $23.3 \mathrm{~g}$ with a standard deviation of $5.7 \mathrm{~g}$ (or $24 \%$ of mean). The cumulative mass measured by the load cell was 723 $\mathrm{g}$, very close to the $725 \mathrm{~g}$ of the filled sample bag measured after the test. These results are very encouraging. Although we have validated it for only one soil type, the carousel and load cell configuration works well for assessing success or failure of sample acquisition and for measuring the discrete and cumulative sample masses.

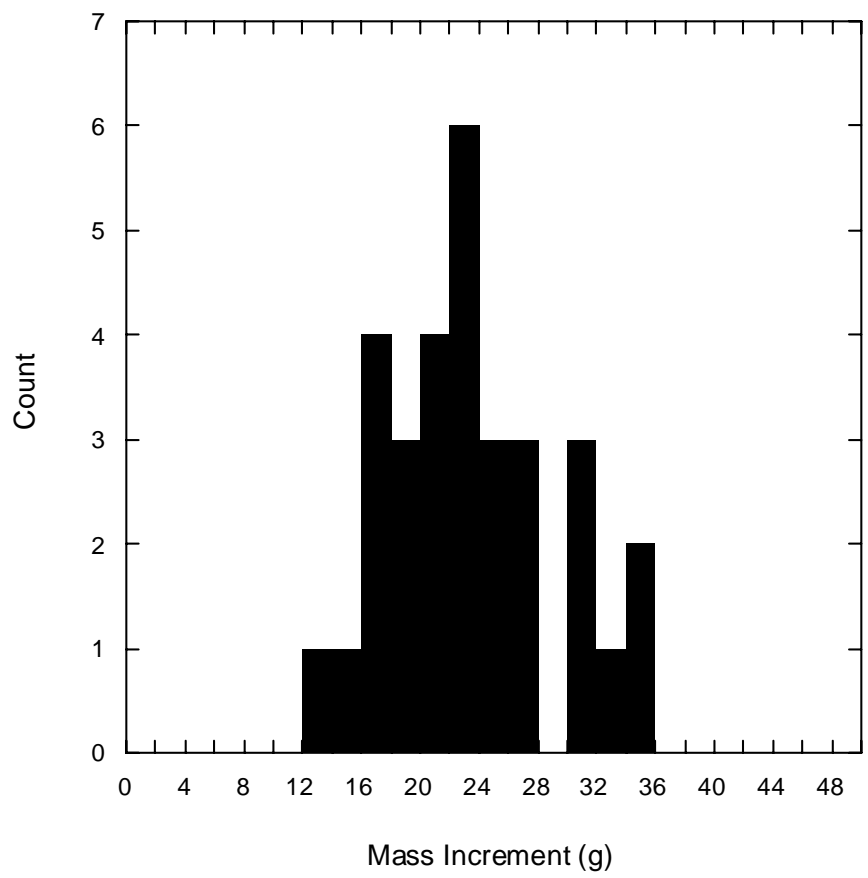

Figure 7. Histogram of 31 samples acquired autonomously in sequence. 


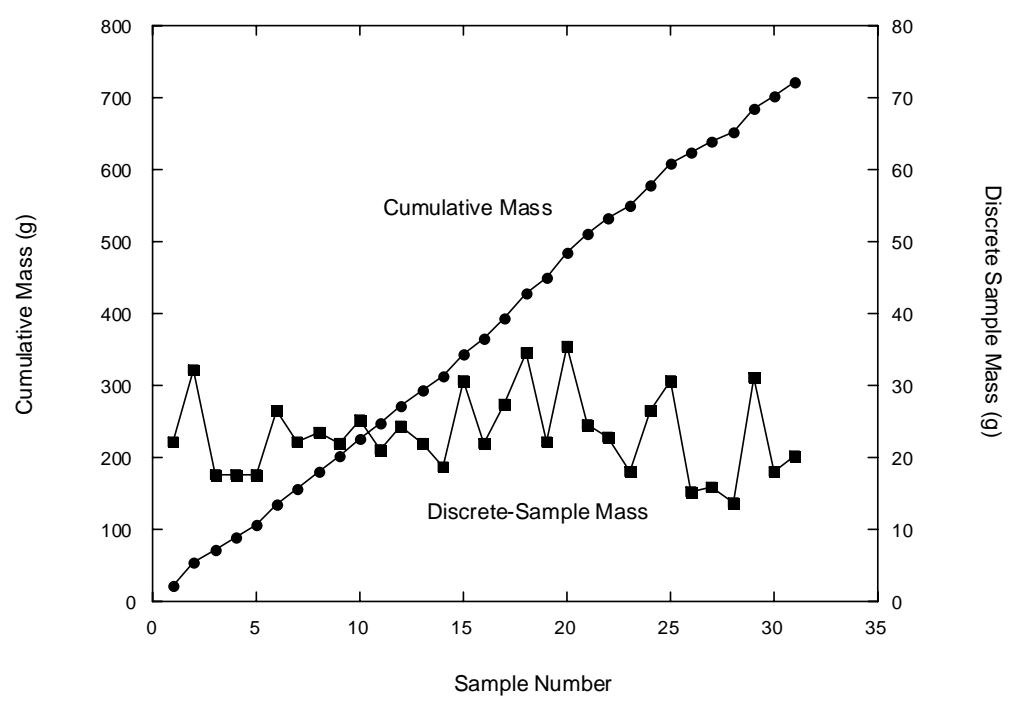

Figure 8. Cumulative and discrete-sample masses of 31 samples acquired autonomously in sequence.

We conducted field tests of the sampler at Canadian Forces Base Gagetown, New Brunswick. The robot executed autonomous sampling lines in two areas where human samplers also collected samples: an access road on an anti-tank range that runs along side the targets (Fig. 9), and the impact area on a hand-grenade range (Fig. 10). Rain and snow melt before and during the tests ensured that the soil moisture was high at both locations. Minor mechanical problems and substantial rain limited sampling times to a couple of hours. The soil was sandgravel, but the sampler had some difficulty dumping the samples from the cutting tube owing to high moisture content. Nevertheless, we obtained four composite samples, two from each location. Explosives residues extracted from these samples show concentrations consistent with human sampling at the same locations (Table 1). 


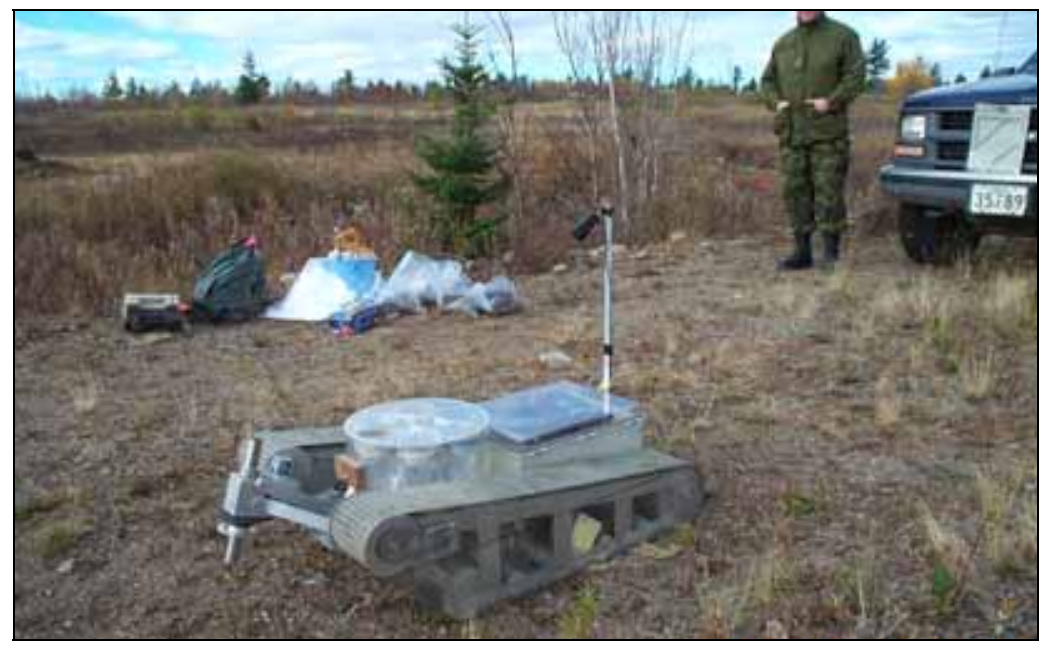

Figure 9. Sampler executing autonomous sampling sequence along an access road adjacent to targets on an anti-tank range at CFB Gagetown.

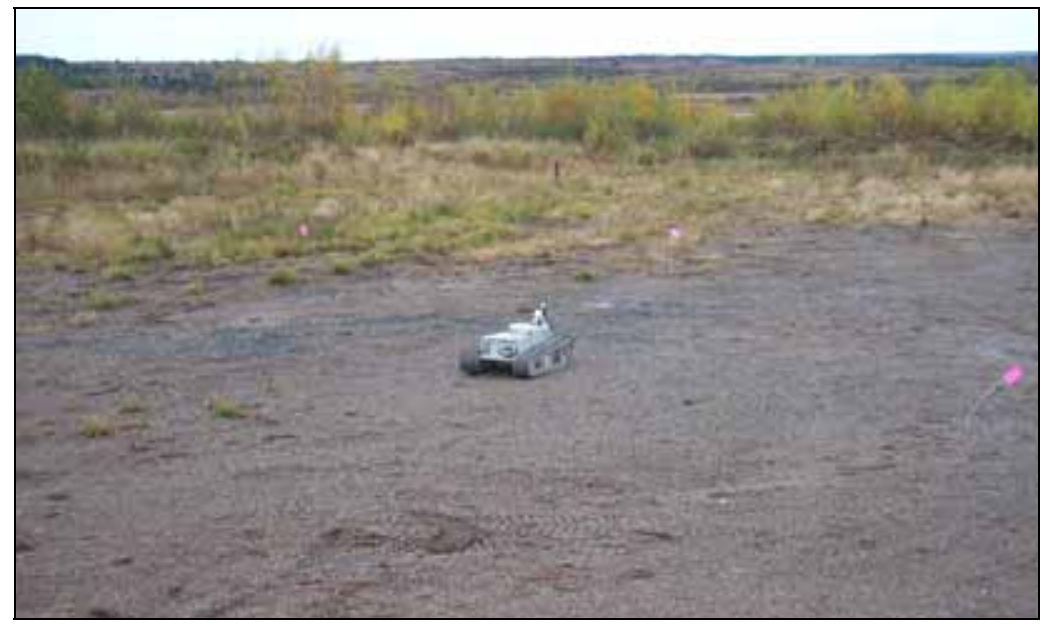

Figure 10. Sampler executing autonomous sampling sequence on impact area of a hand-grenade range at CFB Gagetown.

Mobility displayed by the robot at CFB Gagetown was good because both locations had relatively firm, flat soil with no vegetation. We tried out tracks with 2-cm-high grouser plates as alternatives to our standard tracks to improve traction for loose soil. These proved to be unnecessary, and their increased turning effort significantly impeded maneuverability. 
Table 1. Comparison of HE concentrations in soils collected by human and robotic samplers at CFB Gagetown, October 2003. Numerical values are mg-HE/kg-soil, obtained using the methods described by Jenkins et al. (2001). Only HE residues exceeding detection limits (d) are reported. Given uncertainties in soil sampling for HE residues, the humanand robot-collected samples yielded similar results.

\begin{tabular}{|c|c|c|c|c|c|c|c|}
\hline Location & Sample ID & HMX & RDX & TNT & NG & 2ADNT & 4ADNT \\
\hline $\begin{array}{l}\text { Anti-Tank } \\
\text { Range, Road }\end{array}$ & $\begin{array}{l}\text { Human } \\
18 \\
\text { Human } \\
19 \\
\text { Robot } 1 \\
\text { Robot } 2\end{array}$ & $\begin{array}{l}318 \\
386 \\
\\
62 \\
296\end{array}$ & $\begin{array}{l}0.078 \\
0.120 \\
0.010 \\
0.018\end{array}$ & $\begin{array}{l}3.18 \\
0.432 \\
0.034 \\
0.898\end{array}$ & $\begin{array}{l}17.14 \\
6.74 \\
0.63 \\
1.94\end{array}$ & $\begin{array}{l}0.340 \\
0.332 \\
0.153 \\
0.490\end{array}$ & $\begin{array}{l}0.214 \\
0.218 \\
0.097 \\
0.414\end{array}$ \\
\hline $\begin{array}{l}\text { Hand } \\
\text { Grenade } \\
\text { Range }\end{array}$ & $\begin{array}{l}\text { Human } \\
85 \\
\text { Human } \\
86 \\
\text { Human } \\
88 \\
\\
\text { Robot } 3 \\
\text { Robot } 4\end{array}$ & $\begin{array}{l}<d \\
<d \\
<d \\
0.40 \\
1.72\end{array}$ & $\begin{array}{l}<d \\
<d \\
<d \\
<d \\
<d\end{array}$ & $\begin{array}{l}<d \\
<d \\
<d \\
0.008 \\
<d\end{array}$ & $\begin{array}{l}0.036 \\
0.112 \\
0.256 \\
0.030 \\
<d\end{array}$ & $\begin{array}{l}<d \\
<d \\
<d \\
<d \\
<d\end{array}$ & $\begin{array}{l}<d \\
<d \\
<d \\
<d \\
<d\end{array}$ \\
\hline $\begin{array}{l}\text { Detection } \\
\text { Limits }\end{array}$ & & 0.026 & 0.034 & 0.016 & 0.020 & 0.038 & 0.032 \\
\hline
\end{tabular}




\section{CONCLUSIONS AND FUTURE WORK}

The sampling system with 2.5-cm diameter, three-tooth closed rotary cutter works well in terms of soil versatility, sample-mass consistency, and surfaceparticle collection efficiency, as measured in the laboratory. The system can collect five composite samples, each consisting of 30-50 discrete samples of about $20-50 \mathrm{~cm}^{3}$, depending on the soil type. The mass of each discrete sample is accurately recorded for assessing sample success and mass consistency. We successfully implemented autonomous sampling on our robot using open-loop navigation to execute stratified-random sampling. Tele-operation of the robot permits judgmental sampling and driving between sample locations.

Several improvements and extensions of this work are easily achieved. Although we can log the GPS coordinates of the discrete samples, differential GPS is needed to reduce the error in the coordinates to below $1 \mathrm{~m}$. Use of differential GPS would also allow experimentation with closed-loop navigation strategies, possibly coupled with odometry on the robot. Much more field-testing at firing ranges is also needed to establish the linkage between sampling and mobility requirements and for meaningful statistical comparison between robotic and human sampling results. Mounting the sampling system on a commercial, high-mobility robotic platform would be very useful for such comparisons and to establish an upper bound for production costs. For field tests, it is also important to have a selection of calibrated sample cutters available to adapt to the specific soil conditions on each range. This is straightforward with the present system because the rotary cutters easily swap out. We must also quantify the maximum crosscontamination that results when using the sixth sample bag for cleaning cuts of the rotary tube between composite samples. 


\section{REFERENCES}

Hewitt A.D., T.F. Jenkins, T. Ranney, J. Stark, M.E. Walsh, S. Taylor, M. Walsh, D. Lambert, N. Perron, N. Collins, and R. Karn (2003) Estimates for Explosive Residue Deposition from the Detonation of Army Munitions, ERDC Technical Report TR-03-16, US Army Engineer Research and Development Center.

Jenkins, T.J., J.C. Pennington, T.A. Ranney, T.E Berry Jr., P.H. Miyares, M.E. Walsh, A.D. Hewitt, N.M. Perron, L.V. Parker, C.A. Hayes, and E.G. Wahlgren (2001) Characterization of Explosives Contamination at Military Firing Ranges. ERDC Technical Report TR-01-5, US Army Engineer Research and Development Center.

Taylor S., A. Hewitt, J. Lever, C. Hayes, L. Perovich, P. Thorne, and C. Daghlian (2004) TNT Particle Size Distributions from Detonated 155-mm Howitzer Rounds, Chemosphere, 55: 357-367. 


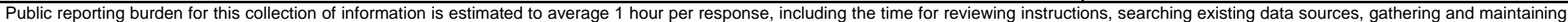

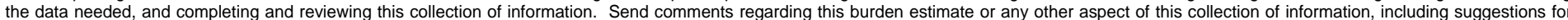

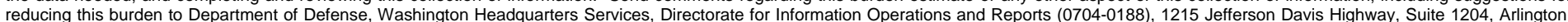

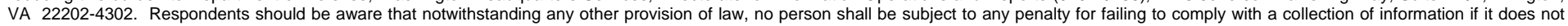
display a currently valid OMB control number. PLEASE DO NOT RETURN YOUR FORM TO THE ABOVE ADDRESS.
1. REPORT DATE 2. REPORT TYPE
June 2004
Technical Report

4. TITLE AND SUBTITLE

Semi-Autonomous Robotic Sampler for Explosives Residues in Surface Soils

3. DATES COVERED (From - To)

5a. CONTRACT NUMBER

5b. GRANT NUMBER

5c. PROGRAM ELEMENT NUMBER

\section{AUTHOR(S)}

\section{5d. PROJECT NUMBER}

James H. Lever, Thomas Nichols, Daniel Denton,* Ryan Meador, Allison Morlock, Jason Kenyon,* Kaitlin Palmer, and Philip G. Thorne

\section{5e. TASK NUMBER}

5f. WORK UNIT NUMBER

\section{PERFORMING ORGANIZATION NAME(S) AND ADDRESS(ES)}

8. PERFORMING ORGANIZATION REPORT

U.S Army Engineer Research and Development Center

Cold Regions Research and Engineering Laboratory NUMBER

Hanover, New Hampshire

ERDC/CRREL TR-04-13

9. SPONSORING I MONITORING AGENCY NAME(S) AND ADDRESS(ES)

10. SPONSOR/MONITOR'S ACRONYM(S)

U.S. Army Environmental Center

Aberdeen Proving Ground, Maryland

11. SPONSOR/MONITOR'S REPORT NUMBER(S)

SFIM-AEC-AT-CR-2004006

\section{DISTRIBUTION / AVAILABILITY STATEMENT}

Approved for public release; distribution is unlimited. Available from NTIS, Springfield, Virginia 22161

\section{SUPPLEMENTARY NOTES}

\section{ABSTRACT}

A 25-kg, dual-track robot was built to satisfy the sampling protocol for surface explosives residues in soils. A rotary-tube cutter takes fairly consistent samples in a variety of soil conditions. Each sample bag holds about 30 samples to form a composite that represents the sampled area. An onboard carousel holds six bags: five composite samples and a sixth bag to clean the tube to minimize crosscontamination. We designed the robot to operate autonomously to collect a composite sample, log the coordinates of the area sampled, complete a composite within about 20 minutes, and operate without intervention for about 2 hours. A person may tele-operate the robot between sampling areas and to and from a base station where batteries and sample bags may be replenished.

\section{SUBJECT TERMS}

Explosives contamination

Range characterization

16. SECURITY CLASSIFICATION OF:

\section{a. REPORT}

$\mathrm{U}$

\section{Robot}

Soil sampling

Sustainable range management

c. THIS PAGE
U

\begin{tabular}{|c|c|} 
17. LIMITATION & $\begin{array}{l}\text { 18. NUMBER } \\
\text { OF ABSTRACT }\end{array}$ \\
OF PAGES \\
\end{tabular}

19a. NAME OF RESPONSIBLE PERSON

19b. TELEPHONE NUMBER (include area code) 